\title{
Hands-on surgical training of congenital heart surgery using 3-dimensional print models
}

\author{
Shi-Joon Yoo, MD, ${ }^{\mathrm{a}, \mathrm{b}}$ Thomas Spray, MD, ${ }^{\mathrm{c}}$ Erle H. Austin III, MD, ${ }^{\mathrm{d}}$ Tae-Jin Yun, MD, ${ }^{\mathrm{e}}$ and \\ Glen S. van Arsdell, MD
}

\section{ABSTRACT}

Objective: Patient-based congenital heart surgery (CHS) training is opportunitybased and difficult. Three-dimensional (3D) print models of the heart were used for hands-on surgical training (HOST) at the 2015 AATS and subsequently in 2 local institutions. We aim to introduce the process of $3 \mathrm{D}$ printing for surgical simulation and to present the attendee's responses.

Methods: Using CT or MR angiograms, the models of congenital heart disease were created and printed with flexible rubberlike material. Altogether, 81 established surgeons or trainees performed simulated surgical procedures with the expert surgeons' guidance and supervision. At the completion of the session, 50 of 81 attendees participated in the questionnaire assessment of the program.

Results: All responders found the course helpful in improving their surgical skills. All would consider including HOST sessions in the training programs. All found that the models showed the necessary pathologic findings. Most found that the consistency and elasticity of the model material were different from those of the human myocardium. However, the responders thought that the quality of the models was acceptable $(88 \%)$ or manageable $(12 \%)$ for surgical practice. The major weaknesses listed were related to the print material and poor representation of the cardiac valves.

Conclusions: HOST using 3D print heart models is achievable and allows surgical practice on pathological hearts without patients' risk. HOST is a highly applicable surgical simulation format for CHS. Incorporation of HOST in training programs could change the traditional opportunity-based education to the requirement-based standardized education. (J Thorac Cardiovasc Surg 2017;153:1530-40)

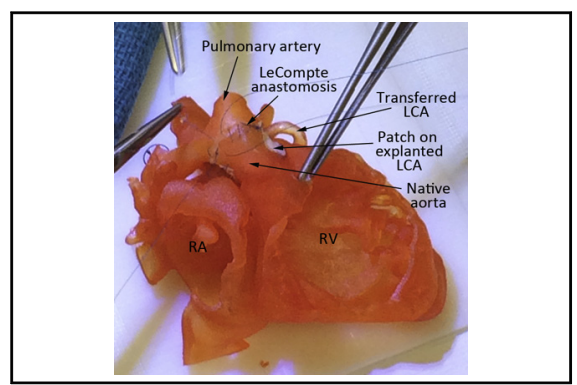

Surgical simulation of arterial switch operation on complete transposition.

\section{Central Message}

Hands-on surgical training (HOST) using 3D print heart models is a highly applicable surgical simulation format for congenital heart surgery.

\section{Perspective}

Hands-on surgical training (HOST) using 3D print heart models could change the traditional opportunity-based training to the requirementbased standardized training and may shorten the training period for congenital heart surgery.

See Editorial Commentary page 1541.

See Editorial page 1528 .
Most significant congenital heart diseases require surgical treatment during infancy or childhood. Congenital heart surgery (CHS) is technically demanding because of the

\footnotetext{
From the ${ }^{\mathrm{a}}$ Department of Diagnostic Imaging, ${ }^{\mathrm{b}}$ Division of Cardiology, Department of Paediatrics, and ${ }^{\mathrm{f}}$ Division of Cardiovascular Surgery, Department of Surgery, Hospital for Sick Children, University of Toronto, Toronto, Ontario, Canada; ${ }^{\mathrm{c}} \mathrm{Di}$ vision of Cardiothoracic Surgery, Department of Surgery, The Children's Hospital of Philadelphia, Perelman School of Medicine, University of Pennsylvania, Philadelphia, Pa; ${ }^{\mathrm{d}}$ Department of Cardiovascular and Thoracic Surgery, University of Louisville, Norton Children's Hospital, Louisville, Ky; and ${ }^{\mathrm{e} D i v i s i o n}$ of Pediatric Cardiac Surgery, Asan Medical Center, Seoul, South Korea.

Institutional Review Board Number and Approval Date: 1000053599, June 1, 2016. Received for publication Sept 16, 2016; revisions received Dec 7, 2016; accepted for publication Dec 29, 2016; available ahead of print March 6, 2017.

Address for reprints: Shi-Joon Yoo, MD, Department of Diagnostic Imaging, Hospital for Sick Children, University of Toronto, 555 University Ave, Toronto, Ontario M5G1X8, Canada (E-mail: shi-joon.yoo@ sickkids.ca).

$0022-5223 / \$ 36.00$

Copyright (c) 2017 by The American Association for Thoracic Surgery

http://dx.doi.org/10.1016/j.jtcvs.2016.12.054
}

wide variation and complexity of pathological anatomy, relative rarity of the individual lesions, and the small size of the heart and vessels. It has been shown that the mortality and morbidity after CHS are affected by the congenital heart surgeon's technical proficiency as well as the institutional and individual surgeon's volumes of surgical cases. ${ }^{1-6}$ However, the trainees of cardiothoracic surgery and CHS fellowship programs are provided with limited operative experience on $\mathrm{CHS}^{7-10}$ Although hands-on surgical

Scanning this QR code will take you to a supplemental video for the article. 


\section{Abbreviations and Acronyms \\ AATS $=$ The American Association for Thoracic Surgery \\ $\mathrm{CAD}=$ computer-aided design \\ CT = computed tomography \\ CHS = congenital heart surgery \\ DICOM $=$ Digital Imaging and Communications in Medicine \\ HOST $=$ hands-on surgical training \\ $\mathrm{MR}=$ magnetic resonance}

training (HOST) is necessary, it is extremely difficult to provide the trainees with opportunities to practice the surgical procedures on the patients without taking risks. Therefore, surgical simulation has increasingly been demanded in training programs. ${ }^{8,11,12}$ Most simulation programs use extracted animal hearts or prosthetic models; however, surgical simulation is hardly applicable for the procedures that are best practiced on the hearts with actual pathology.

Three-dimensional (3D) printing allows fabrication of models using 3D volume image data of the patient's computed tomography (CT), magnetic resonance (MR), or echocardiography. ${ }^{13}$ When they are printed with flexible rubberlike material, the models can be used for surgical practice. ${ }^{14,15}$ A hands-on training course of CHS using 3D print models was held for the first time at the 2015 Annual Meeting of The American Association for Thoracic Surgery (AATS) and subsequently in Seoul, Korea, and Toronto, Canada.

The present article was aimed to introduce the technical details for 3D printing of the models for HOST, to present the responses and evaluations of the attendees of the HOST courses, and to discuss the future directions.

\section{MATERIALS AND METHODS}

\section{Three-Dimensional Printing Technique}

Contrast-enhanced CT or MR angiograms were used for 3D printing. The original DICOM (Digital Imaging and Communications in Medicine) image data were postprocessed by using commercially available software programs (Mimics 10 and 3-matics18; Materialise, Leuven, Belgium). The cardiac cavities and vessel lumens were segmented using automatic thresholding; manual editing with drawing, erasing, and local thresholding tools; region growing; and volume rendering (Figure 1, A). Using 2D multiplanar and $3 \mathrm{D}$ volumerendered images, the areas that were not needed for printing were removed. As the image quality was not adequate for clear delineation of the valve structures for $3 \mathrm{D}$ printing, only the valvar attachments were represented on the models. Six to 10 valvar insertion points were marked on the $2 \mathrm{D}$ and/or $3 \mathrm{D}$ images and connected using the function called "spline" (Figure 1,B).

The volume-rendered DICOM image files thus produced were converted to the STL (Standard Tessellation Language) files for computeraided design (CAD) and printing. It is theoretically ideal to have the full-thickness myocardium and vessel wall segmented for printing. However, delineating the epicardial surface of the heart is a time-consuming and laborious process, as the epicardial surface is not distinctly and accurately definable because of a relatively small difference in signal intensities between the myocardium and soft tissues. Furthermore, fullthickness models made of the commercially available print materials are too stiff to be used for surgical practice. As an alternative method, a shell with a thickness of 1.2 to $1.8 \mathrm{~mm}$ was graphically added on the outer surface of the segmented cast of blood pool by using the CAD function called "hollow" (Figure 2,A). Although the outer surface of the shell does not represent the real anatomy, the inner surface represents the precise endocardial surface anatomy on which most of the surgical procedures are performed. By using the CAD cutting tool, the vessels entering and leaving the heart and the surgical access routes were made open. For cardiac valvar annuli, the splined valvar attachments were given a 0.8 - to $1.2-\mathrm{mm}$ thickness by using CAD sketch and design tools. The model was then placed on a graphically designed platform so that it can be plastered on the table (Figure $2, B$ ). When required, the model was supported by additional graphically designed supporting stools. The completed models of the heart, valvar annuli, and platform were saved as STL files in a folder for 3D printing. The postprocessing and CAD described previously were performed by the experienced cardiac imager (S.J.Y.).

Three-dimensional printing was performed on a commercially available 3D printer (Objet Connex 260 printer; Stratasys Ltd, Eden Prairie, Minn) using the most flexible material (TangoPlus FullCure resin) for the heart, a solid material (VeroWhite) for the platform and stools, and mixture of the 2 print materials for valvar annuli. Printing took 5 to 7 hours for each model. The estimated cost for 5 to 7 hours of printing was $\$ 150$ to $\$ 210$, assuming that the operating time of the printer used was 30 hours per week for 5 years. The average cost for print materials per model was $\$ 60$. The supporting material was thoroughly removed using waterjet, fine brushes, and ear-spoons and by immersing in sodium hydroxide solution. The cleaned models were used either as produced or dyed with a slightly dark color for improved perceptual representation of the surface anatomy (Figure 3). Cleaning and dying took approximately 1 hour on average for each piece of model by the hands of a layman who had 7 years of experience.

\section{HOST Sessions}

Annual Meeting of the AATS (April 25, 2015). Sixty surgeons registered for the 2-hour course. It was planned to provide each attendee with 3 models, as shown in Table 1. Because of the limited allocated time, 1 of 2 cases of double-outlet right ventricle and a case of hypoplastic left heart syndrome were used for surgical practice. The techniques for repair were briefly demonstrated with slides by the moderator. The attendees were divided into groups of 2 and alternated the roles of the primary operator and assistant. Four proctors were available throughout the course.

Congenital Heart Disease Center Symposium, Asan Medical Center, Seoul, Korea (December 6, 2015). Ten surgical trainees who were partnered with the established surgeons (altogether 20 attendees) registered for 1 full-day course. Each attendee was provided with $3 \mathrm{D}$ print models of the same cases that were used for the AATS (Table 1). Each hands-on session was preceded by a 15-minute lecture on surgical pathology and a 20-minute case presentation. The organizers advised the surgeons to attend the course with their colleague cardiologists and radiologists. The organizers aimed to provide the cardiologists and radiologists with opportunities to have better understanding of the surgical procedures by assisting their colleague surgeons. Three senior surgeons were invited as proctors.

HOST 2016, Hospital for Sick Children, Toronto, Canada (January 7-9, 2016). A 2.5-day intensive course was organized for a small group of surgeons. Each attendee was provided with 5 models, as listed in Table 1. Each hands-on session was preceded by a 
File Edit View Image Measure Segment Analyze Align 3DTools Help

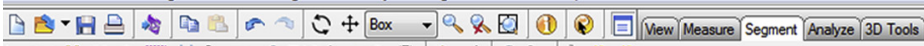

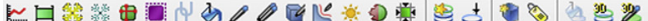
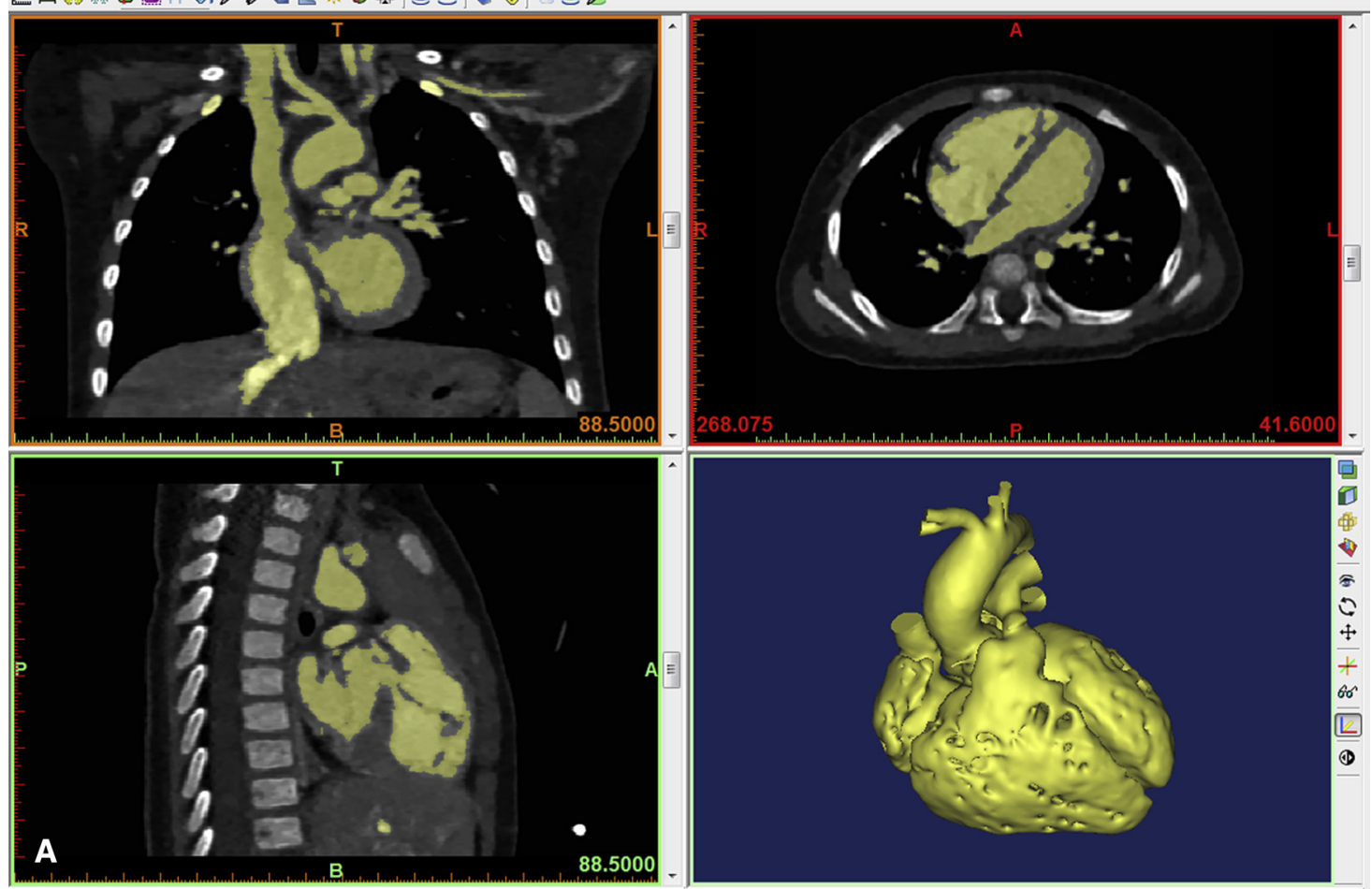

File Edit View Image Measure Segment Analyze Align 3D Tools Help

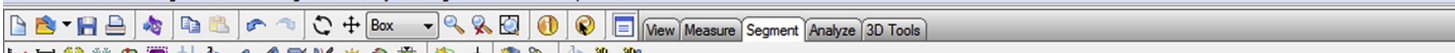

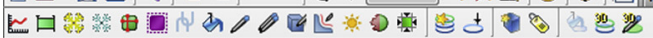
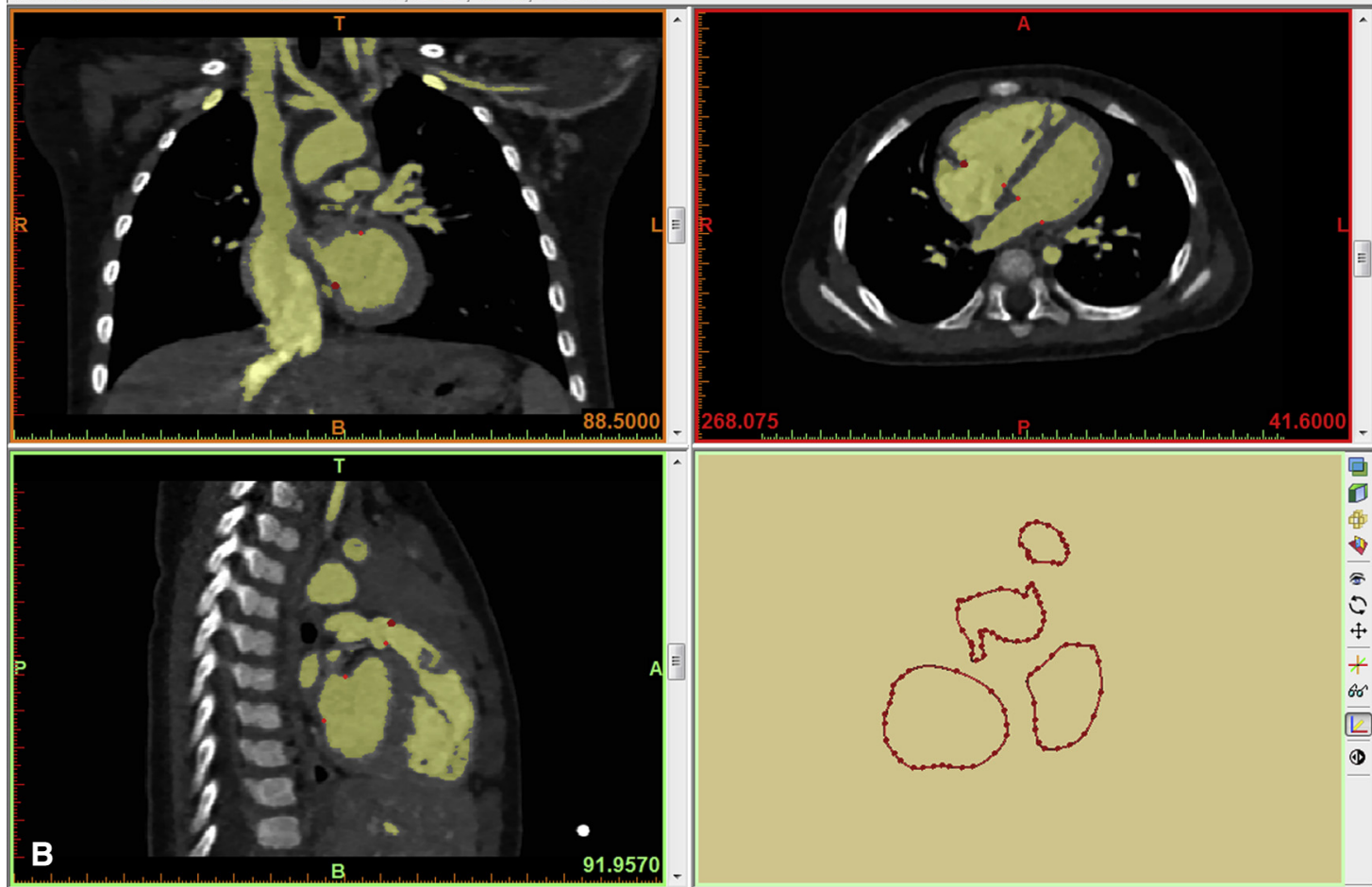

FIGURE 1. Segmentation process in a commercially available software program (Mimics 10; Materialise, Leuven, Belgium) using computed tomography angiograms from a patient with tetralogy of Fallot. A, Segmentation on multiplanar sectional images using thresholding and manual edition with a volumerendered image in the right lower panel. B, Linear representation of cardiac valvar attachment sites. Six to 20 attachment points of each valve are marked and connected by using a tool called "spline." 

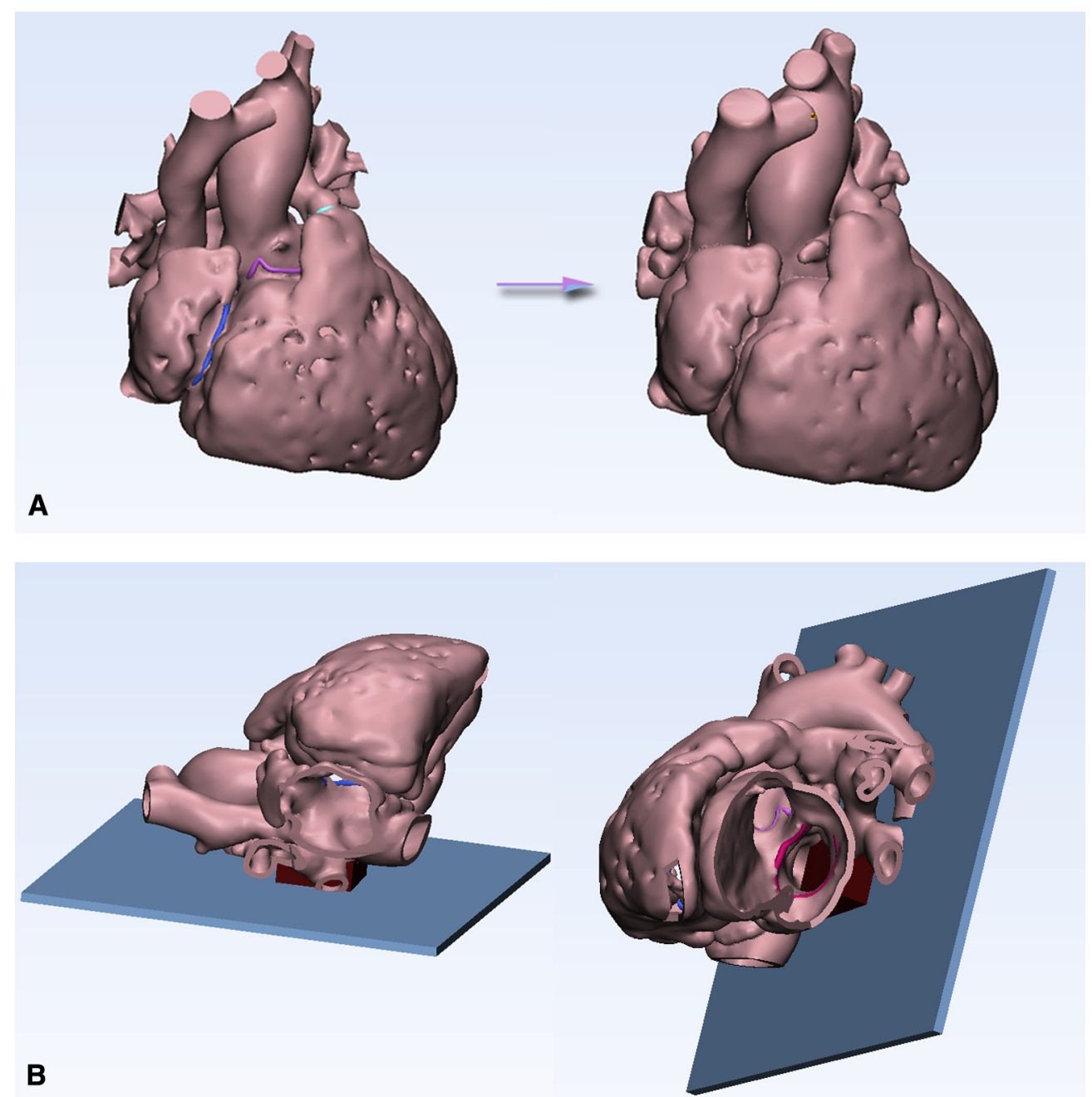

FIGURE 2. Three-dimensional volume-rendered images showing the process of computer-aided design of the models for surgical practice using a commercially available software program (3-matics 18; Materialise, Leuven, Belgium). A, A shell with a thickness of 1.2 to $1.8 \mathrm{~mm}$ is added on the cavity. B, The ends of the vessels were open and the route for surgical approach was created by removing a part of the right atrial wall. The left ventricular free wall was also removed so that the surgical results can be easily inspected. The model was mounted on a graphically designed platform.

30-minute lecture on surgical pathology and skills or demonstration of the procedure on the model. The attendees were divided into groups of 2 and alternated the roles of the primary operator and assistant. Three proctors were available throughout the course. Each hands-on session was followed by the proctors' evaluation and comments on the attendees' surgical performance.

The example of the surgical procedures is shown in Figure 4 and Videos 1 to 3 . At the end of the session, the attendee surgeons were asked to answer a set of questions, as listed in Tables 2-4.

\section{RESULTS}

Fifty $(62 \%)$ of 81 attendees participated in the survey. The attendees' responses are summarized in Figure 5 and Tables 2-4. The attendees had 1 to 30 years of experience in cardiovascular surgery.

All who responded found the course helpful in improving their surgical skills. All would consider including HOST sessions in the training programs for residents and fellows. All found that the models showed the necessary pathologic findings. Most found that the consistency and elasticity of the model material were different from those of the human myocardium. However, the responders thought that the quality of the models was acceptable $(88 \%)$ or manageable $(12 \%)$ for surgical practice.

The listed weaknesses of the models for surgical practice are summarized in Table 3. The major weaknesses listed were related to the print material and poor representation of the cardiac valves and their supporting structures.

The attendees produced a wish list of a variety of lesions to be dealt with in future courses (Table 4). The most common lesions on the wish list were complete transposition, tetralogy of Fallot, atrioventricular septal defect, and double-outlet right ventricle. 

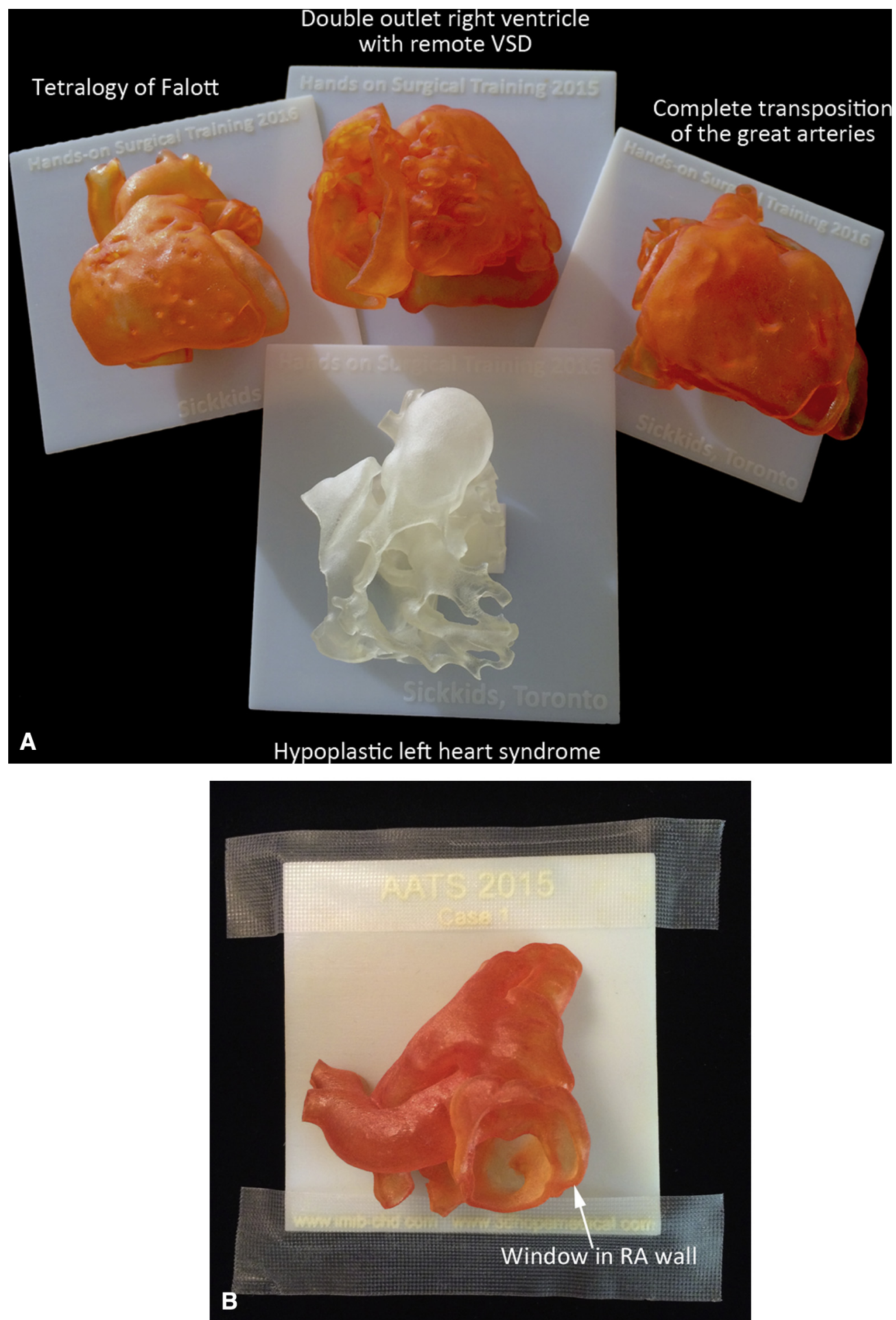

FIGURE 3. Four example models for surgical simulation. Colored model is preferred to white or light beige-colored model (A). Slightly dark color improves the perception of complex surface anatomy. For hands-on practice, the model is plastered on the table (B). VSD, Ventricular septal defect; RA, right atrium.

\section{DISCUSSION}

Traditional surgical training relies on so-called "Halstedian" preceptorship: the orderly exposure to graduated clinical experience in the operating room during several years of residency under the close tutelage of dedicated senior attending surgeons. ${ }^{16,17}$ The Halstedian preceptor-apprenticeship on an operating table is reliant on opportunistic encounters. As individual types of 
TABLE 1. List of cases used for hands-on surgical training

\begin{tabular}{ccc}
\hline $\begin{array}{c}\text { CHD Center } \\
\text { of AATS, } \\
\text { Baltimore, Md }\end{array}$ & $\begin{array}{c}\text { Medical Center, } \\
\text { Seoul, Korea }\end{array}$ & $\begin{array}{c}\text { HOST 2016, Hospital } \\
\text { for Sick Children, } \\
\text { Toronto, Canada }\end{array}$ \\
\hline DORV with & DORV with & Tetralogy of Fallot \\
subaortic VSD & subaortic VSD & Transposition of the great \\
DORV with & DORV with & arteries for arterial switch \\
remote VSD & remote VSD & HLHS for Norwood operation \\
HLHS for & HLHS for & DORV with remote VSD \\
Norwood & Norwood & DORV with subpulmonary \\
operation & operation & VSD (Tasussig-Bing) \\
\hline
\end{tabular}

AATS, American Association for Thoracic Surgery; $C H D$, congenital heart disease; $H O S T$, hands-on surgical training; DORV, double-outlet right ventricle; VSD, ventricular septal defect; HLHS, hypoplastic left heart syndrome.

various forms of congenital heart diseases are often rare and show complex and variable morphology, CHS requires a long training period if the training relies largely on observation, assistance, and supervised practice. In addition, the observation of the primary operator's procedure is often difficult, as the procedure is performed through a small surgical window that can be easily blocked by the hands of the operator and assistants as well as the surgical instruments, especially when the procedure is performed on a small infant's heart. Simulation provides the surgeons with ample opportunity to experience a wider variety of pathologic conditions without any time constraint and to master surgical skills without putting the patient's health and life at risk.

Simulation of CHS can be performed either virtually on a computer screen or on a physical structure, such as an explanted animal heart or prosthetic model. A virtual surgical simulator has been proven particularly useful in learning robotic surgical procedures. ${ }^{18}$ However, the virtual reality or virtuality provided by the computer-based simulator is far from satisfactory in practicing manual surgical procedures, as the surgical manipulation is not directly on the object structure but through the handles of the simulator. Although explanted animal hearts can be used for the procedures that can be simulated in normal hearts such as the arterial switch procedure, the Ross-Konno procedure, and valve repairs or replacement, simulation on an animal heart is not applicable for most CHS procedures.

Three-dimensional printing technology allows fabrication of physical models of human organs using DICOM data obtained by CT, MR, or ultrasound. The utility of 3D print models in surgical planning and education in the medicine of congenital heart disease has been discussed elsewhere. ${ }^{13}$ The application of 3D printing has expanded to surgical training very recently. The 3 HOST courses presented in this article are the first attempts of utilization of $3 \mathrm{D}$ print models for simulation courses of
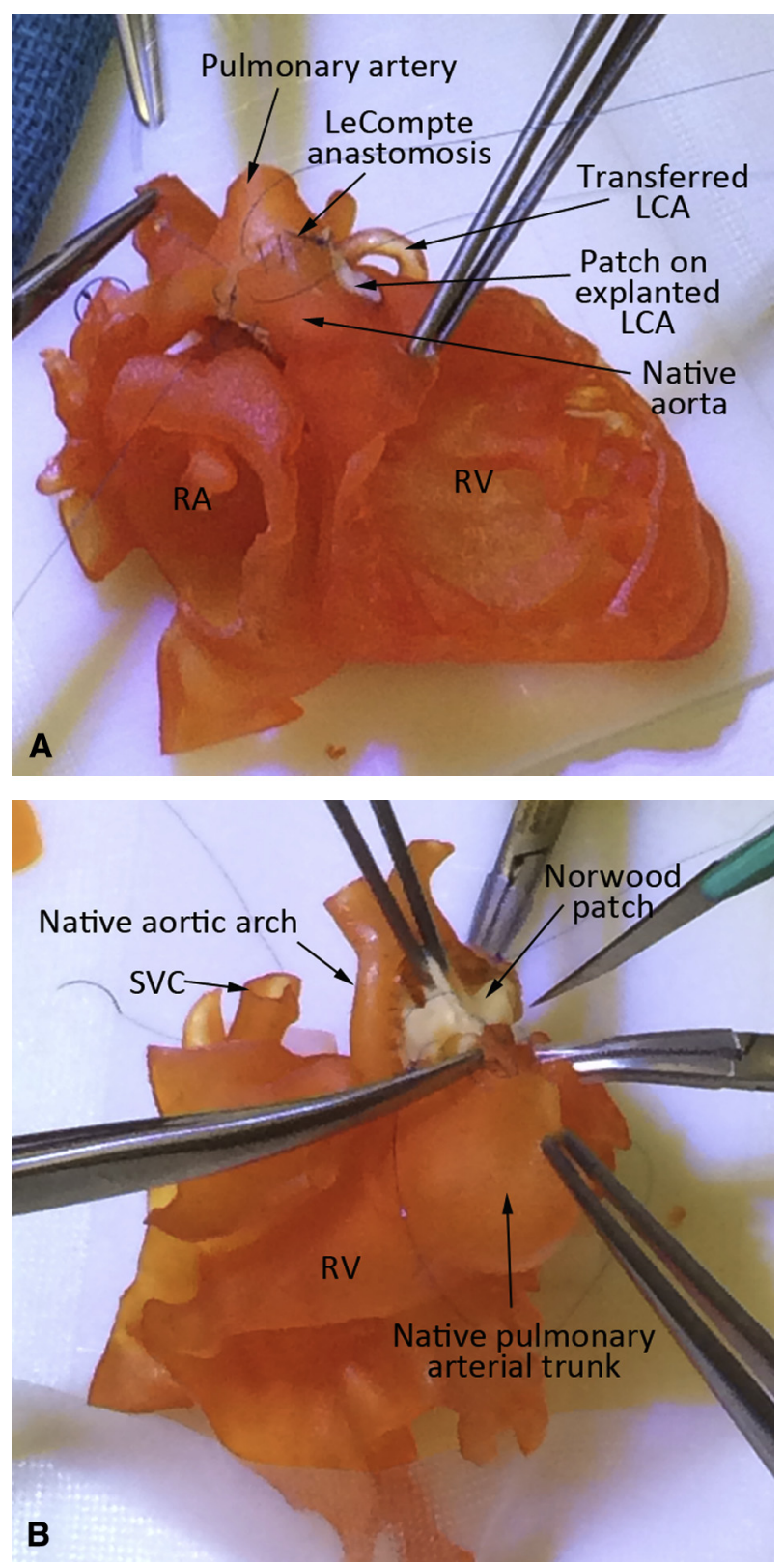

FIGURE 4. Scenes of surgical procedures on the models. A, Arterial switch operation in complete transposition of the great arteries. B, Norwood operation in hypoplastic left heart syndrome with aortic atresia. $L C A$, Left coronary artery; $R A$, right atrium; $R V$, right ventricle; $S V C$, superior vena cava.

CHS. Practicing the surgical procedures on the physical models reduces the gap between the reality and virtuality. As shown in the results, the attendees' responses were extremely promising, with $48 \%$ of the responders finding the models highly acceptable and 52\% finding them acceptable or manageable for simulation surgery.

However, there are limitations and weaknesses of CHS simulation using 3D print models. The currently available 


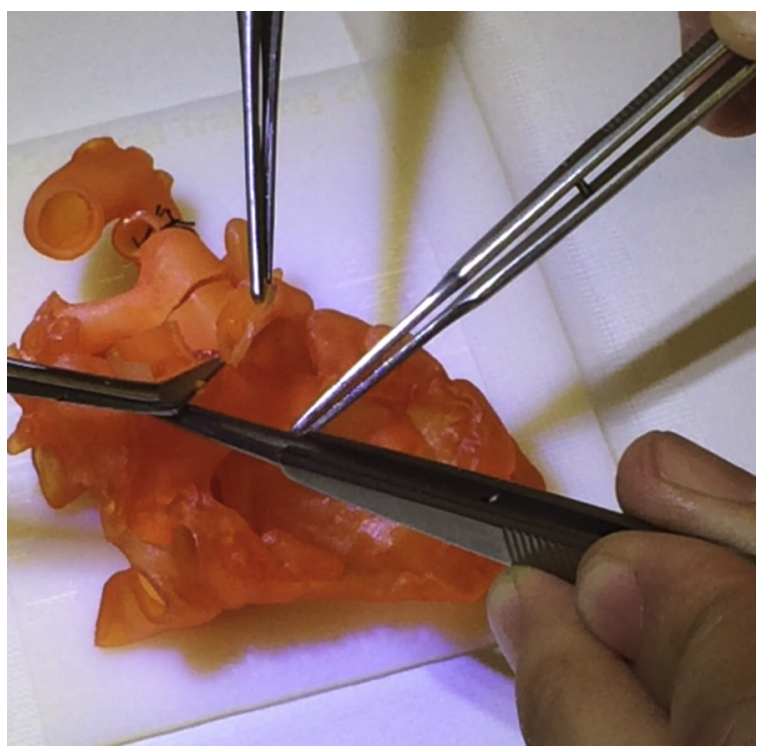

VIDEO 1. Scenes of hands-on surgical training on a model with complete transposition of the great arteries. Excision of the left coronary arterial button from the aortic wall. Video available at: http://www.jtcvsonline.org/ article/S0022-5223(17)30184-8/addons.

print materials are not completely satisfactory, as the physical properties, including consistency, elasticity, and tensile strength, are different from those of the human myocardium and endocardium. The surgeons found that

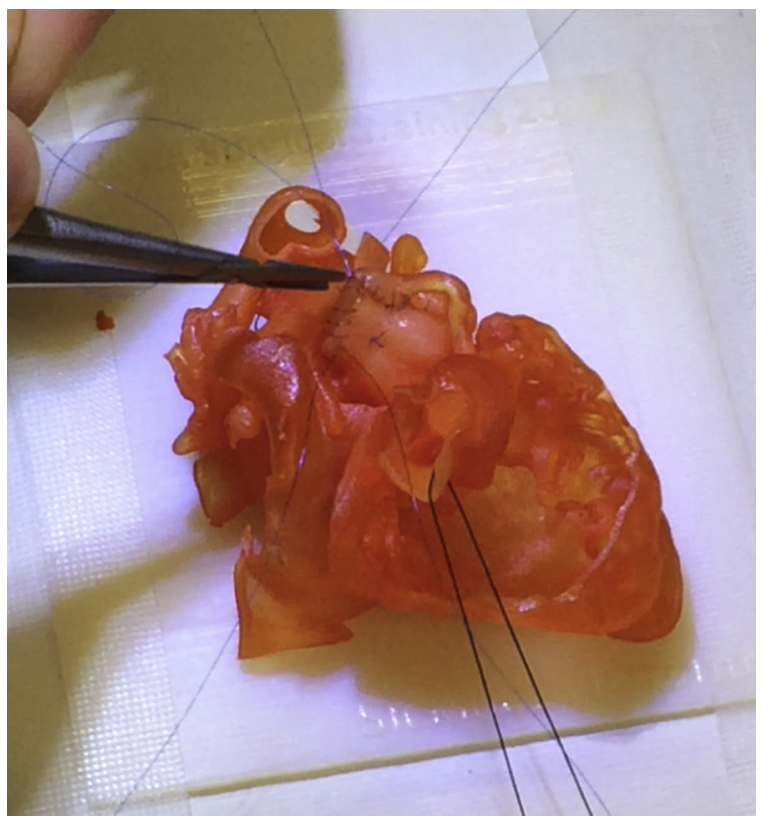

VIDEO 2. Scenes of hands-on surgical training on a model with complete transposition of the great arteries. Implantation of the left coronary artery button to the main pulmonary artery. Video available at: http://www.jtcvsonline. org/article/S0022-5223(17)30184-8/addons.

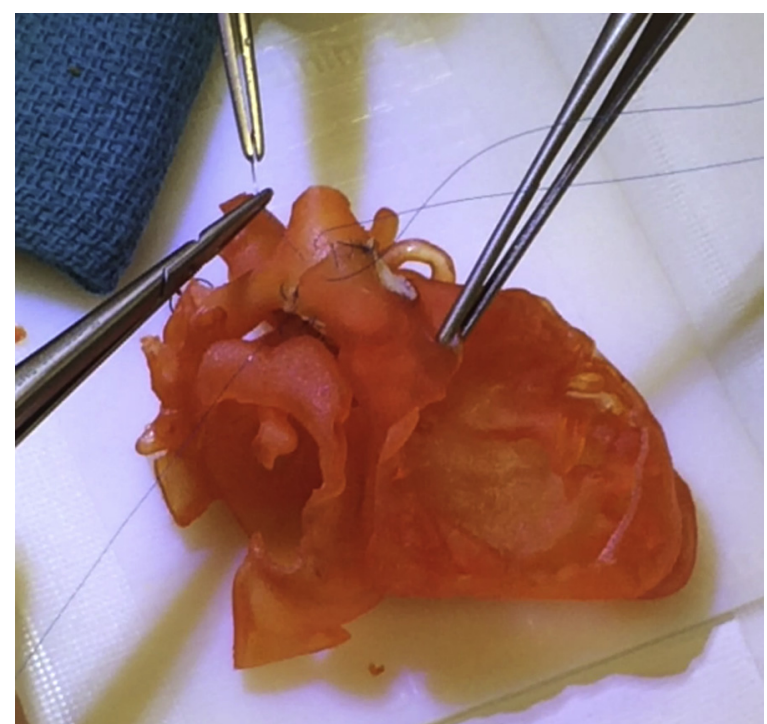

VIDEO 3. Scenes of hands-on surgical training on a model with complete transposition of the great arteries. Establishment of pulmonary arterial connection using Lecompte maneuver. Video available at: http://www.jtcvsonline.org/ article/S0022-5223(17)30184-8/addons.

the models made of flexible material are more difficult to be sewn and are easily torn or cut through as compared with the real tissues. High-quality silicone appears to be an ideal material that provides the physical properties close to those of human tissue. Although a 3D printer using silicone has not been commercially available, a few companies have recently announced the release of $3 \mathrm{D}$ printers using silicone. ${ }^{13}$ Alternatively, flexible models can be made using an injection molding technique in which molds are printed with a 3D printer and gel materials, such as silicone and urethane, are infused into the mold. ${ }^{14}$ Although it is applicable, it involves 1 more step that requires time, labor, and additional cost at the expense of a degree of inaccuracy.

The cardiac valves and chordae tendineae are important structures that need to be represented in the 3D print models for surgical simulation. Using currently available

\section{TABLE 2. List of questions}

How many years have you performed cardiovascular surgery?

Did the models provide you with the necessary information regarding the major pathological findings?

How would you grade the overall quality of the models you operated on? Was the consistency and elasticity of the model material similar to that of the human myocardium?

Was the model material acceptable for an appropriate surgical simulation? Did you find this Hands-on Surgical Simulation Session helpful in improving your surgical skills?

Would you consider including similar Hands-on Surgical Simulation Sessions in the training programs for residents and fellows? 
TABLE 3. List of the weaknesses of the models

\begin{tabular}{lc}
\hline \multicolumn{1}{c}{ Weaknesses } & Number \\
\hline Difficult suture and/or easy cut through & 12 \\
Valves and supporting structures, not shown & 11 \\
Inadequate consistency and elasticity of material & 4 \\
Material different from human tissue & 3 \\
Wall structures, not fully shown & 3 \\
Chest wall, not modeled & 1 \\
Not able to be reused & 2 \\
Expensive & 1 \\
\hline
\end{tabular}

imaging technology and print materials, the valves and chordae tendinae are difficult to reproduce in the 3D print models. As an alternative solution for surgical simulation, we are in the process of developing fake valvar and chordal structures that can be applied to the 3D print heart models. Using CAD programs, valves and chords are graphically designed and printed with the heart models. Figure 6 shows the prototype valves we designed in a normal heart.

As cardiovascular surgical procedures are performed through an incision in the chest wall, it would be ideal to have the patient's chest wall, mediastinal structures, and pericardium, as well as the heart and great vessels represented in the simulation model. Although it is labor intensive and expensive to produce, the overlying structures on the path of surgical approach can be printed together. Alternatively, the 3D print heart model can be placed in a plastic torso simulating the chest wall and the underlying structures in a similar way that has been used for simulation with prosthetic models. ${ }^{19-21}$

Cardiovascular surgical procedures, as well as cardiopulmonary bypass, can be simulated on a living animal.

TABLE 4. Wish list of the pathologic entities or procedures in the forthcoming courses

\begin{tabular}{lc}
\hline \multicolumn{1}{c}{ Congenital heart disease or procedure } & Number \\
\hline Complete transposition & 10 \\
Tetralogy of Fallot (with atrioventricular septal defect) & $8(1)$ \\
Atrioventricular septal defect & 8 \\
Double outlet right ventricle & 8 \\
Congenitally corrected transposition & 6 \\
Total anomalous pulmonary venous connection & 6 \\
Coarctation of the aorta or hypoplasia of the aortic arch & 6 \\
Hypoplastic left heart syndrome & 4 \\
Ventricular septal defect & 4 \\
Heart disease in heterotaxy syndrome & 4 \\
Borderline left ventricular hypoplasia & 2 \\
Interruption of the aortic arch & 2 \\
Truncus arteriosus & 2 \\
Criss-cross heart & 2 \\
Fontan operation & 2 \\
Ross-Konno procedure & 1 \\
\hline
\end{tabular}

However, it is expensive, laborious, and hardly applicable. When a surgical procedure needs to be simulated on a beating heart, a prosthetic model or explanted animal heart is connected to mechanical pumps to generate cardiac pulsation. ${ }^{21,22}$ It is considered possible to design a heart model with threaded tubes attached to the venous and arterial sides of the heart so as that the $3 \mathrm{D}$ print heart can be connected to the pumps.

The attendees listed various congenital heart diseases in their wish lists for future courses. The lesions involving the ventriculoarterial regions including complete and congenitally corrected transpositions, doubleoutlet right ventricle, tetralogy of Fallot, and truncus arteriosus are most commonly listed. The obstructive lesions of the aortic arch with or without left ventricular hypoplasia were also commonly listed. Threedimensional print models for surgical simulation of most listed lesions can be provided. We were able to make excellent models of hypoplastic left heart syndrome that allowed the Norwood operation. However, it required extensive and careful manual work after printing, as the luminal diameter of the ascending aorta was only $1.5 \mathrm{~mm}$ and the supporting material had to be completely removed without damaging the wall. It would be challenging to make models for atrioventricular septal defect because of the difficulty in representing the valvar and supporting structures in the 3D models, as discussed previously. We plan to develop the models printed with a graphically designed common or partitioned atrioventricular valve in place. Surgical simulation models for suture-less repair of pulmonary venous pathology requires the models printed within the pericardial sac so that a suture-less technique of pulmonary venous repair can be performed, which is another challenging goal.

We believe that HOST with 3D print models is the best applicable CHS simulation program among the currently available options. All responders agreed that the HOST was helpful in improving their surgical skills and that HOST programs should be considered in the training programs of the surgical residents and fellows. HOST with 3D print models is important for several reasons. First, traditional opportunity-based training can be changed to requirement-based training by using the $3 \mathrm{D}$ print models that are developed for standardized surgical training. Second, the risk to patients' health and life during the learning period of the surgical procedures can be minimized. Third, a surgical simulation program using 3D print replicas can be disseminated to any number of institutions and, therefore, can be easily standardized throughout the country and even over the world. Surgical simulation does not have to be at the site where the experienced supervisors are available. As there is no constraint in time, the trainees can do the procedures 
Model provided necessary information on pathology.

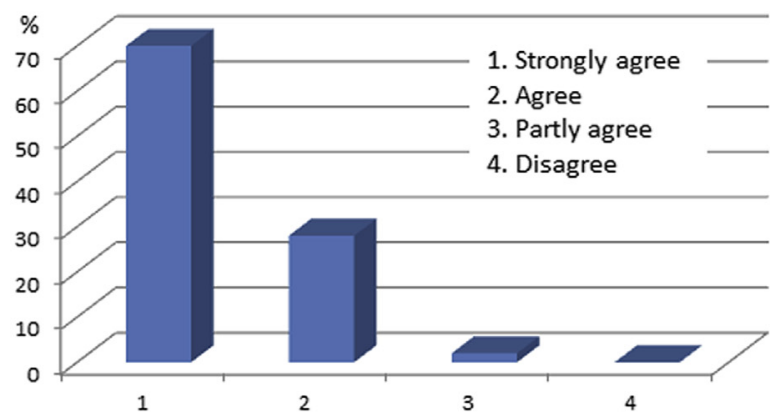

Consistency and elasticity of model materal similar to human myocardium

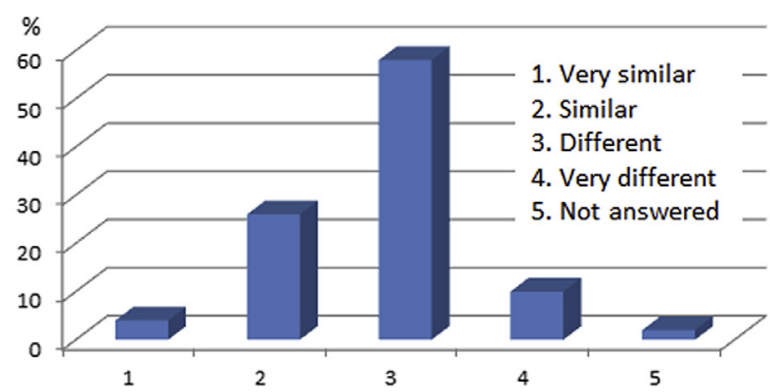

HOST helpful for improvement of sugical skills

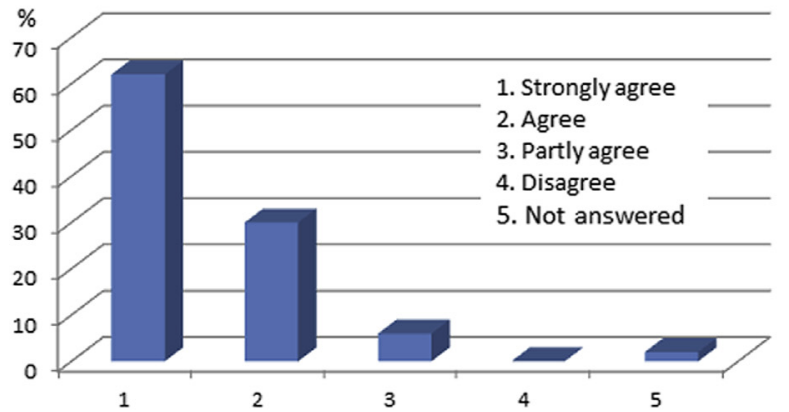

Quality of model for surgical simulation

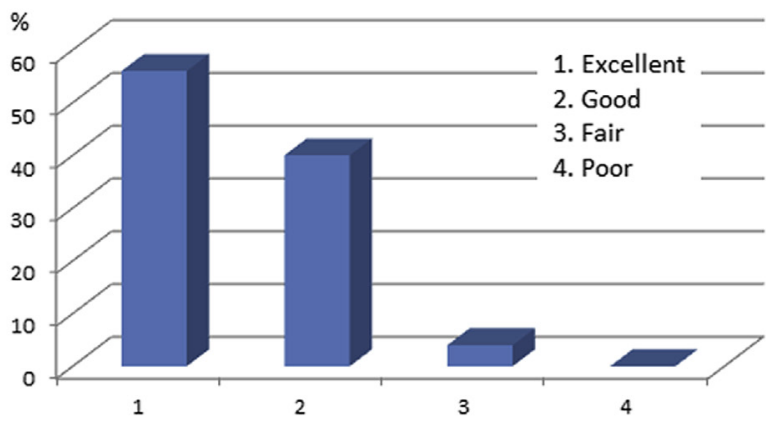

Model material was accepable for surgical simulation.

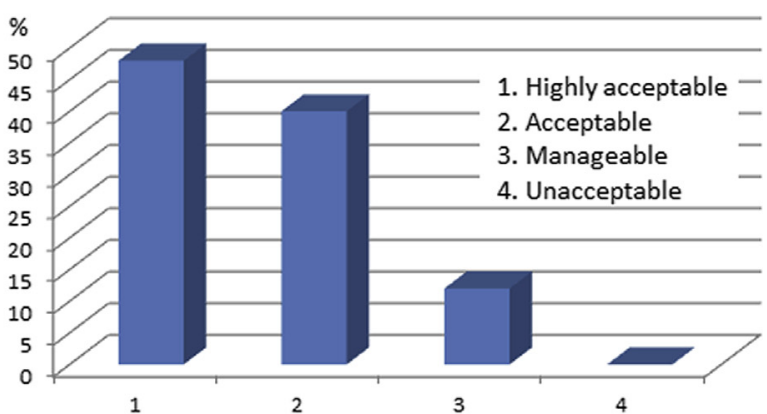

Would you include courses similar to HOST in your resident or fellowship training program?

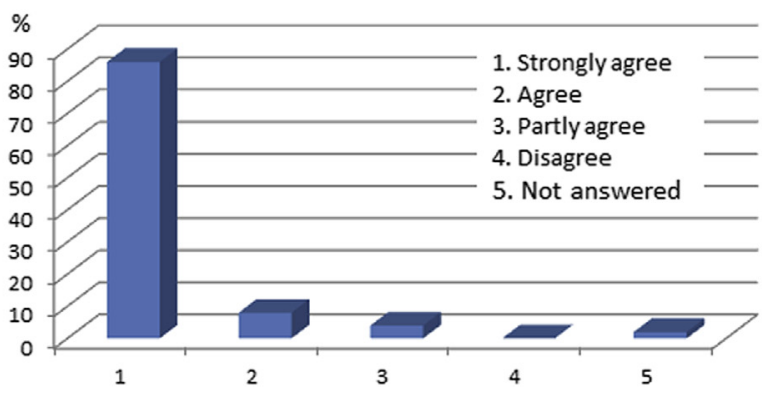

FIGURE 5. Attendees' responses to questionnaire. HOST, Hands-on surgical training.

under the guidance of the supervisor over real-time video from a remote site. The models on which the trainees performed surgical simulation can be sent to the supervisor for their evaluation and comments. Finally, the training period can be shortened by providing the trainees with the definable and achievable goals of hands-on training using 3D print models.

For the procedures that require a complex form of surgical patch, the required patch can be graphically designed and printed preoperatively. ${ }^{23}$ The $3 \mathrm{D}$ print patch model can be used as the template for trimming the surgical patch to be sewn on the patient's heart either before or during the surgery. Furthermore, newly developed surgical procedures can be tested on 3D print models before actual trial on patients.

A shared repository of image data will allow 3D printing of various types and variations of congenital heart diseases for morphology teaching and surgical simulation. ${ }^{24,25}$ Thereby, surgeons anywhere in the world can enjoy the opportunity to perform simulation procedures on the infrequently as well as frequently encountered congenital heart diseases. ${ }^{11}$ Furthermore, simulation of existing and newly introduced procedures using 3D print models could contribute to worldwide standardization of the surgical procedures and permit "cross-fertilization" of ideas between centers. ${ }^{11}$ 

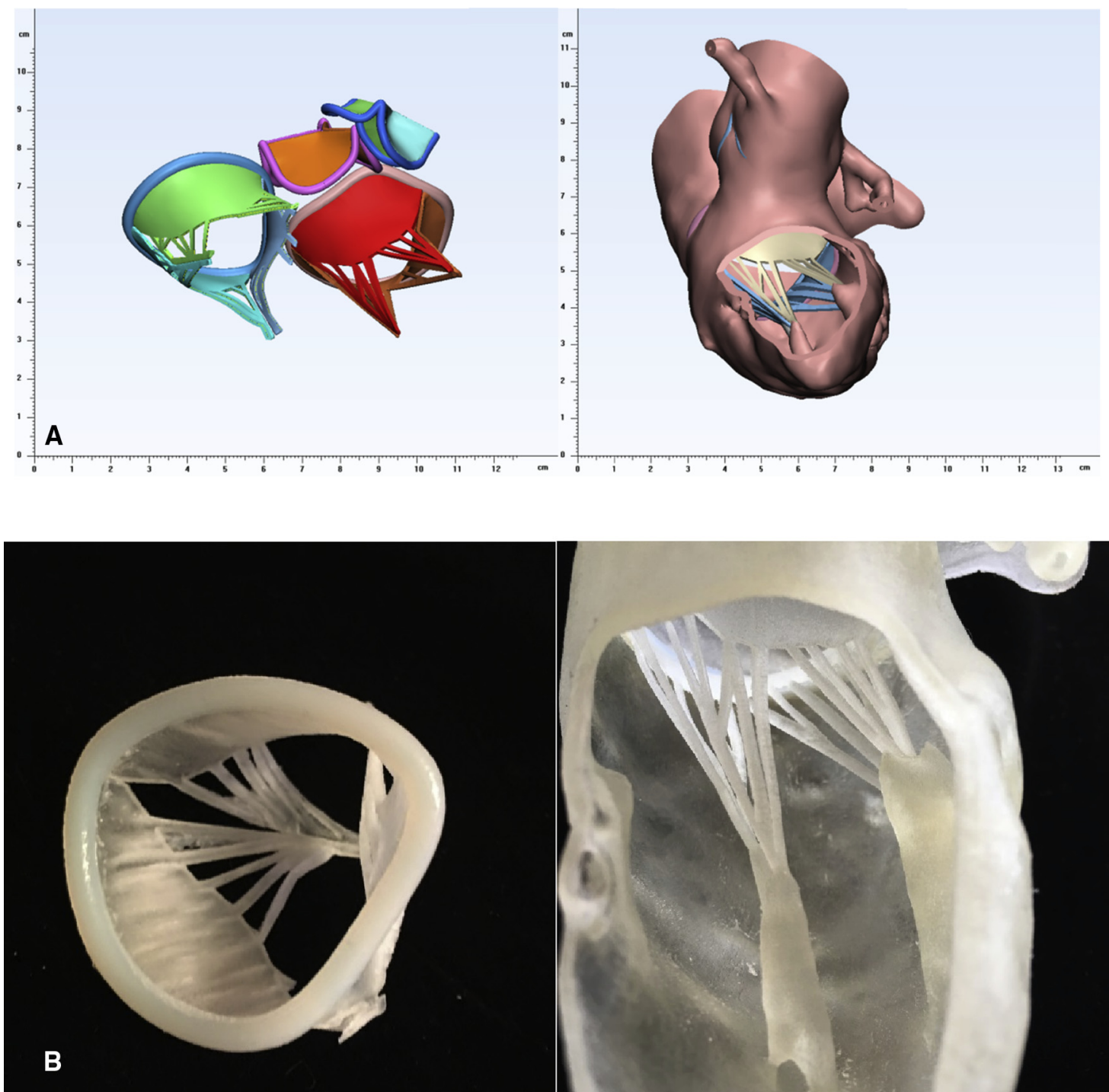

FIGURE 6. Graphically designed cardiac valves. A, Cardiac valve leaflets and chordae tendineae are graphically designed along the splined curve of the valve annulus (left). The designed mitral valve is combined with the wall model of the left ventricle (right). B, Printed tricuspid valve (left) and the mitral valve printed with the left ventricle (right).

\section{Conflict of Interest Statement}

Dr Yoo is the owner of a 3D printing company, 3D HOPE (Human Organ Printing and Engineering) Medical, and the chief officer of the not-for-profit organization International Medical Image Bank for Congenital Heart Diseases. All other authors have nothing to disclose with regard to commercial support.

\section{References}

1. Nathan M, Karamichalis JM, Liu H, Emani S, Baird C, Pigula F, et al. Surgical technical performance scores are predictors of late mortality and unplanned reinterventions in infants after cardiac surgery. J Thorac Cardiovasc Surg. 2012; 144:1095-101.e7.

2. Shuhaiber J, Gauvreau K, Thiagarjan R, Bacha E, Mayer J, Del Nido P, et al. Congenital heart surgeon's technical proficiency affects neonatal hospital survival. J Thorac Cardiovasc Surg. 2012;144:1119-24.
3. Welke KF, Diggs BS, Karamlou T, Ungerleider RM. The relationship between hospital surgical case volumes and mortality rates in pediatric cardiac surgery: a national sample, 1988-2005. Ann Thorac Surgery. 2008;89:889-96.

4. Welke KF, O'Brien SM, Peterson ED, Ungerleider RM, Jacobs ML, Jacobs JP. The complex relationship between pediatric cardiac surgical case volumes and mortality rates in a national clinical database. J Thorac Cardiovasc Surg. 2009;137:1133-40.

5. Hornik CP, He X, Jacobs JP, Li JS, Jaquiss RD, Jacobs ML, et al. Relative impact of surgeon and center volume on early mortality after the Norwood operation. Ann Thorac Surg. 2012;93:1992-7.

6. Jacobs JP, O'Brien SM, Pasquali SK, Jacobs ML, Lacour-Gayet FG, Tchervenkov CI, et al. Variation in outcomes for risk-stratified pediatric cardiac surgical operations: an analysis of the STS Congenital Heart Surgery Database. Ann Thorac Surg. 2012;94:564-71.

7. Lange R, Hoerer J, Schreiber C. What are the obstacles to training in surgery for congenital heart disease in Germany? Thorac Cardiovasc Surg. 2013:61:273-7.

8. Stephens EH, Odell D, Stein W, LaPar DJ, DeNino WF, Aftab M, et al. A decade of change: training and career paths of cardiothoracic surgery residents 2003 to 2014. Ann Thorac Surg. 2015;100:1305-13. 
9. Chu D, Vaporciyan AA, Iannettoni MD, Ikonomidis JS, Odell DD, Shemin RJ, et al. Are there gaps in current thoracic surgery residency training programs? Ann Thorac Surg. 2016;101:2350-5.

10. Kogon B, Karamlou T, Baumgartner W, Merrill W, Backer C. Congenital cardiac surgery fellowship training: a status update. J Thorac Cardiovasc Surg. 2016; 151:1488-95.

11. Carpenter AJ, Yang SC, Uhlig PN, Colson YL. Envisioning simulation in the future of thoracic surgical education. J Thorac Cardiovasc Surg. 2008;135: 477-84.

12. Feins R. Expert commentary: cardiothoracic surgical simulation. J Thorac Cardiovasc Surg. 2008;135:485-6.

13. Yoo SJ, Thabit O, Kim EK, Ide H, Yim D, Dragulescu A, et al. 3D printing in medicine of congenital heart diseases. $3 D$ Printing in Medicine. 2016;2:3.

14. Shiraishi I, Yamagishi M, Hamaoka K, Fukuzawa M, Yagihara T. Simulative operation on congenital heart disease using rubber-like urethane stereolithographic biomodels based on 3D datasets of multislice computed tomography. Eur J Cardiothorac Surg. 2010;37:302-6.

15. Costello JP, Olivieri LJ, Krieger A, Thabit O, Marshall MB, Yoo SJ, et al. Utilizing three-dimensional printing technology to assess the feasibility of high fidelity synthetic ventricular septal defect models for simulation in medical education. World J Pediatr Congenit Heart Surg. 2014; 5:421-6.

16. Halsted WS. The training of the surgeon. Bulletin of the Johns Hopkins Hospital. 1904; 15:267-75.

17. Barnes RW, Lang NP, Whiteside MF. Halstedian technique revisited. Innovations in teaching surgical skills. Ann Surg. 1989;210:118-21.

18. Sørensen TS, Greil GF, Hansen OK, Mosegaard J. Surgical simulation - a new tool to evaluate surgical incisions in congenital heart disease? Interact Cardiovasc Thorac Surg. 2006;5:536-9.
19. Fann JI, Caffarelli AD, Georgette G, Howard SK, Gaba DM, Youngblood P, et al. Improvement in coronary anastomosis with cardiac surgery simulation. J Thorac Cardiovasc Surg. 2008;136:1486-91.

20. Helder MR, Rowse PG, Ruparel RK, Li Z, Farley DR, Joyce LD, et al. Basic cardiac surgery skills on sale for $\$ 22.50$ : an aortic anastomosis simulation curriculum. Ann Thorac Surg. 2016;101:316-22.

21. Reuthebuch O, Lang A, Groscurth P, Lachat M, Turina M, Zünd G. Advanced training model for beating heart coronary artery surgery: the Zurich heart-trainer. Eur J Cardiothorac Surg. 2002;22:244-8.

22. Ramphal PS, Coore DN, Craven MP, Forbes NF, Newman SM, Coye AA, et al. A high fidelity tissue-based cardiac surgical simulator. Eur J Cardiothorac Surg. 2005;27:910-6.

23. Giannopouk AA, Chepelev L, Shikh A, Wang A, Dang W, Akyuz E, et al. 3D printed ventricular septal defect patch: a primer for the 2015 Radiological Society of North America (RSNA) hands-on course in 3D printing. 3D Printing in Medicine. 2015;1:3.

24. Yoo SJ, Thabit O, Lee W, Goo HW, van Arsdell GS. Double outlet right ventricle in your hands. Available at: http://imib-chd.com/wp-content/uploads/ morphology/1-dorv-in-your-hands/DORV\%20IN\%20YOUR \%20HANDS \% 2012\%20CASE\%20SERIES.pdf. Accessed February 24, 2017.

25. Yoo SJ, Thabit O, Lee W, Goo HW, Yim D, Ide H, et al. Most peculiar hearts in your hands. Criss-cross, superoinferior, twisted, topsy-turvy, etc. What do they all mean? Available at: http://imib-chd.com/wpcontent/uploads/morphology/2-mph-in-your-hands/MOST $\% 20$ PECULIAR $\%$ 20HEARTS $\% 20$ IN $\% 20$ YOUR $\% 20$ HANDS $\% 20$ Full $\% 20$ Pages.pdf. Accessed February 24, 2017.

Key Words: hands-on surgical training, congenital heart surgery, 3D printing, 3D print models, surgical simulation 